\title{
Dy 0 mort.
}

Die bortiegenbe Shrift enthält bie Inmenbung ber Rehren bes Strafenbauts auf ben Balbwegbaut mit ben fitr biefe Disciplin uäthizen Mobificationen. Sie fudt außerbem bie güđen ju ergänzen, welde bie allgemeine Straßenbaulehre für ben $2 B a l b w e g b a u$ nod

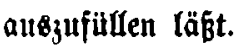

$\Im_{\mathfrak{n}}$ wie weit bem $\mathfrak{B e r f a f f e r}$ beiber gelungen - bieß z̆ beur= theilen ïberläßst ex Denjenigen, welde fí fđon praltifめ mit bem Warbwegbau in eingehenter Beife beidäftigt haben.

Für biejentigen Rejer, bei welden bieß niфht ber Fafl ift, bemertt ver Berfaffer, baß fie fï niфt etwa burd ben formelreiden 3nbalt

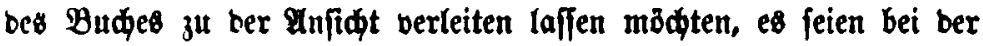

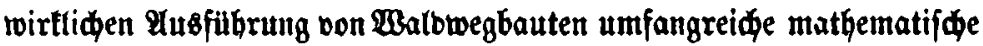
Entrwiatlungen nothpenbig. Denn bei jener wenbet man bie wenigiten ber mitgetheilten Formeln birect an; bie ubertwiegenbe MRebrjabt berjelben bient nur zur Begrïnbung aflgemeiner Regeln unb tommt besbalb bann nidt mehr in Betradt, wenn fid ber Rejer bon ber Riøtigteit ber Enorejultate ubergeugt hat. Nur an bie lekteren Gält er fíd in ber Praxis; er madt bon benferben Bebraud, obne jebermal bie (Entwidtungen zu mieberkolen*).

*) So nimmt, um nur Cin Beilpiel ju geben, bie matbematifde Begrinbung bes Berfabrens : projectirte Befautinien fofort (obne weiteres Brobiren) in befinitive, b. b. in folde jut bertwanbeln, welde eine be. liebige, wenn therbaupt möglide, Erbmaffenantsleidung bewirlen, neun bolle Seiten (bon 29 bis 37) ein. Filtr ben praltijळen Bebraud reiden aber bie formeln (21) unb (25) ars Enbrejultate bolltommen aus unb verwanbeln fí nod fut bie getoöbntid borlommenben ffolle in bie gang einfaden Specialformeln (22) unb (23), beziebungsweife in (26) unb (27). 
Bleiben aud für mande befonbers widtige autgaben in ber Braris now umfaffenbere Redinungen ju beforgen, to befteben biefe nur in ber Subftitution ber auf bem Rocale 2 . exhobenen Broben in bie allgemeinen Formeln, um bie von jebem concreten Falle

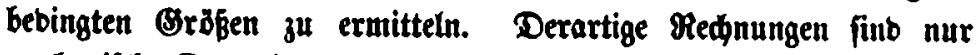
medanifhe Dperationen, welde burd bereits borkanbene ober now ju conftruirenbe Silfotabellen bebeutend abgefïrgt und vereinfadgt werben tonnen.

Die in unferer Sdurift entbaltenen Rängen $=$ Flähen $=$ Raum=, unb Bemidts = Bröben fint in Brob̧herjoglid Defiridem MRaaje angegeben. Bum Behuf ber Umwanblung in anbere Ranbesunabe

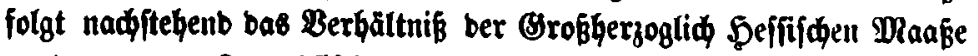
3u bem neuten zranzofifidien.

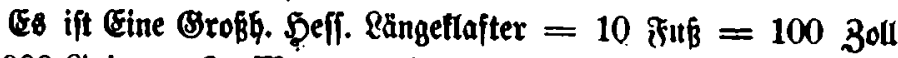
$=1000$ Rinien $=2.6$ Meter unb jonad, Ein Rängefú $=0.25$ Meter;

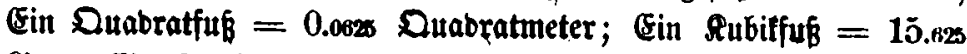
Siter; Eill Stecten a 100 Stubitfuk $=1.0025$ Steren. Ferner ift Ciin Morgen à 40000 Quabratfuß ober 4C0 Quabratrutben $=25$ Aren. Enblid ift Ein $\$$ frund $=500$ Bramm.

Gięen im Suni 1864.

Sluato sener. 